\title{
A PRE-EXPERIMENTAL STUDY ON THE EFFECT OF DRAIN FRIENDLY JACKETS ON COMFORT IN POST MASTECTOIMY SUBJECTS IN WARDS OF A SELECTED HOSPITALS IN A IMETROPOLITAN CITY
}

\section{Ms Apurva Atmaram Yenji}

\author{
Faculty, Holy Spirit Institute of Nursing Education.
}

Research Problem: A pre-experimental study on the effect of Drain Friendly Jackets on Comfort in post mastectomy subjects in wards of a selected hospitals in a metropolitan city.

Primary Objective: To compare the level of comfort in post mastectomy subjects with and without use of Drain Friendly E Jackets.

Research Methodology: Population of the study was subjects underwent mastectomy post operatively with drains day 1 in a hospital. The investigator used comfort assessment tool to assess the comfort levels in the patient pre \& postintervention. Opinionnaire taken for the intervention given. Study was conducted with 45 subjects.

if Results: The comfort score was assessed Drain Friendly Jacket was given to the subjects, there was a significant difference between comfort level achieved while using the jacket compared to the without use of jacket with an average comfort score for with jacket and without jacket and with it is statistically significant.

Conclusion: Findings of the study indicated that Drain Friendly Jacket has helped to improve subjects comfort during post mastectomy period. Patient were able comfortably perform their routine tasks.

\section{INTRODUCTION}

Breast conditions and associated surgical interventions have an impact on quality of life. Relatively little is known about the extent of effect in breast surgery populations, the products available in the market for the women who have gone through, mastectomy or bilateral mastectomy. The closed wound drainage system used for breast cancer subjects immediately following mastectomy requires external drainage tubes that connect to a pouch. Post-mastectomy survivors face several socio emotional as well as medical issues that call for optimized apparel and accessories for that can provide comfort, support and enhanced physical appearance. We designed a Drain Friendly Jacket and assessed its usefulness in enhancing comfort in post mastectomy subjects admitted to a tertiary care hospital, India.

Breast cancer is the most frequent cancer among women, impacting 2.1 million women each year, and causes the greatest number of cancer-related deaths among women. In 2018 , it is estimated that 627,000 women died from breast cancer - that is approximately $15 \%$ of all cancer deaths among women. While breast cancer rates are higher among women in more developed regions, rates are increasing in nearly every region globally. ${ }^{1}$ Globally, Incidence of Breast cancer $11.6 \%$ population of 2.089 million of all new cases of Cancer for both sexes, worldwide in $2018 .{ }^{2}$ Breast cancer is the most common cancer in women in India according to GLOBOCAN and accounts for $27 \%$ of all cancers in women. Incidence rises in the early thirties, peaks at 50-64 years. Approximately $48 \%$ are below 50 years of age. ${ }^{3}$ According to GLOBOCAN, in 2018, 1,62,468 new cases and 87,090 deaths were reported for breast cancer in India. Making Breast Cancer ranked as number one in category of new cancer cases and cause of death due to cancer. 5-year prevalence is $4,05,456$ cases has been observed in India. Both sexes combined, breast cancer is the most observed cancer ( $14 \%$ of the total cases) and it is the leading cause of cancer death ( $11 \square 1 \%$ of the total cases) in India ${ }^{4}$

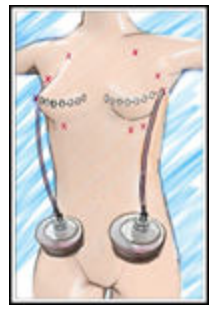

Figure 1: Front perspective of a postmastectomy subject's body with the placement of a closed drainage system

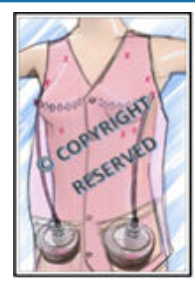

Figure 2: Front perspective of a postmastectomy subject's body with the placement of a closed drainage system within the drain friendly jacket.

\section{OBJECTIVES OFTHE STUDY}

\section{-Primary Objective:}

To compare the level of comfort in post mastectomy subjects with and without use of Drain Friendly Jackets

\section{-Secondary Objectives:}

To associate level of comfort with demographic \& clinical variables.

To elicit opinionnaire about Drain Friendly Jacket among post mastectomy patient

\section{Table 1: Data Gathering Process}

\begin{tabular}{|c|c|c|c|}
\hline & Pretest & Intervention & Post test \\
\hline $\begin{array}{l}\text { Single } \\
\text { Group }\end{array}$ & $\begin{array}{l}\text { Pre-test on day } 1 \\
\text { in post } \\
\text { mastectomy } \\
\text { subjects that is } 24 \\
\text { hours after } \\
\text { surgery assessing } \\
\text { the level of } \\
\text { comfort. }\end{array}$ & $\begin{array}{l}\text { Drain Friendly } \\
\text { Jacket given to } \\
\text { the subjects. }\end{array}$ & $\begin{array}{l}\text { Post-test on the } \\
\text { day when } \\
\text { removal of } \\
\text { drainage bottle } \\
\text { is planned to } \\
\text { assess the level } \\
\text { of comfort post } \\
\text { intervention. }\end{array}$ \\
\hline
\end{tabular}

\section{MATERIALS AND METHODS}

An experimental single group pretest post-test design was used in the study. Ethics clearance and permissions were obtained and written informed consents were taken from participants. Total 45 patients who had undergone mastectomy and who met with the inclusion criteria of having drain from the first post-operative day were assigned to the use of intervention [Drain Friendly Jacket]. Women were given Drain Friendly Jackets to wear till the drain was kept. Comfort was assessed with the Comfort Assessment Tool which included physical, psychospiritual, environmental, and sociocultural characteristics. Finally, opinions were elicited about the acceptability of the Drain Friendly Jacket from the participants in the group. 


\section{RESULTS}

With regard to comfort score, there was a significant difference between comfort level achieved while using the jacket compared to the without use of jacket in post mastectomy patients with an average comfort score for with jacket $(46.8000+4.8317)$ and without jacket $(37.7111+3.2726)$ and with $(\mathrm{P}<0.0001)$ it is statistically significant .There was no significant difference in the comfort level $(p=0.8705)$ with regard to age groups. With regards to type of mastectomy, double mastectomy patients showed slightly higher comfort level score (average score of 49.3333) compared to patients who had undergone modified unilateral radical mastectomy (average score of 46.6190).

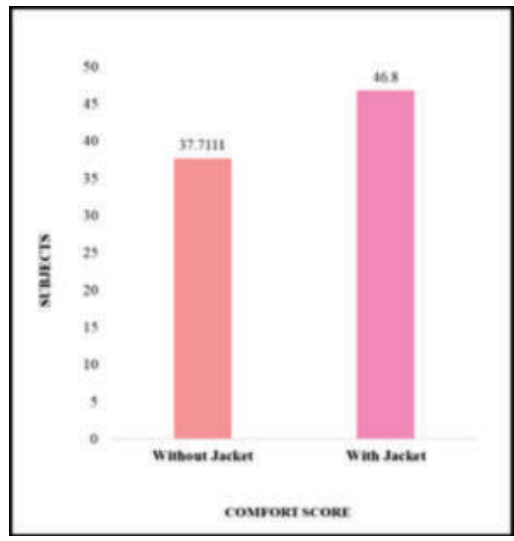

Figure 3: Association of comfort score without and with jacket in type of drain

The response to opinionnaire indicated that $93.33 \%$ patients found the Drain Friendly Jacket being convenient to use, 80\% patients felt smarter wearing the Drain Friendly Jacket, and $86.67 \%$ patients agreed that Drain Friendly Jacket has userfriendly design. Majority patients (84.44\%) agreed that the Drain Friendly Jacket has helped them to cope with the situation better after surgery. Also $84.44 \%$ patients would recommend Drain Friendly Jacket to other patients who required to use similar drainage bottles.

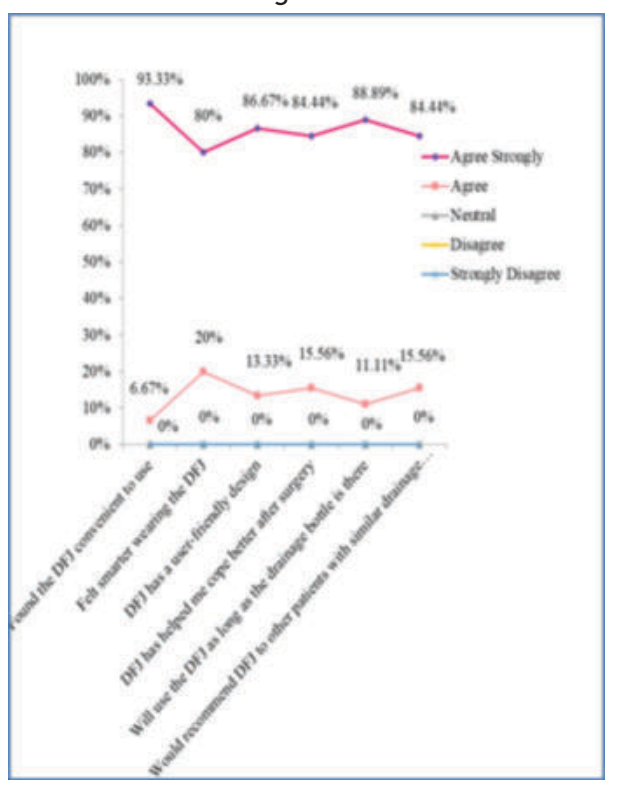

Figure 4: Distribution of subjects in relation to their opinion about the intervention

\section{CONCLUSIONS}

Not only postoperatively a mastectomy patient comes across pain but also discomfort associated with Drainage Bottles. Care of drainage bottle is important as it has major importance in the recovery phase furthermore for a good prognosis. A patient comes across Body Image issues which are promptly seen in post-mastectomy subjects. Drain Friendly Jacket had significantly enhanced comfort in postmastectomy subjects and was able to perform tasks, ROM exercise and even carried the drainage bottle with them without any discomfort.

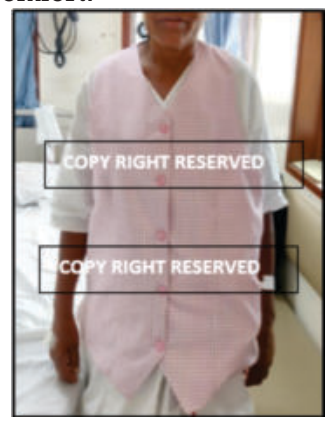

Image 1 : Subject wearing Drain Friendly Jacket (DFJ)

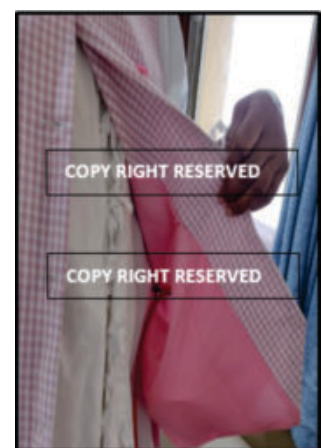

Image 2: Subject carrying drain bottle in Drain Friendly Jacket (DFJ)

\section{REFERENCES:}

1. Breast Cancer. World Health Organisation. [Internet]. who.int. 2018 [cited 18 September 2019].

2. New Global Cancer Data: GLOBOCAN 2018 uicc Global Cancer Control [Internet].uicc.org. 2018 [cited 17 September 2019].

3. Ferlay J. et al. Cancer incidence and mortality worldwide: Sources, methods and major patterns in GLOBOCAN 2012. International Journal of Cancer. 2014;136(E359-86)

4. India Globocan 2018. Cancer fact sheets [Internet]. Cancer Today gco.iarc. fr. 2018 [cited 17 September 2019]. 